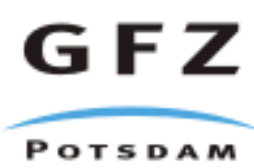

Originally published as:

Marquardt, H., Ganschow, S., Schilling, F. R. (2009): Thermal diffusivity of natural and synthetic garnet solid solution series. - Physics and Chemistry of Minerals, 36, 2, 107-118

DOI: $10.1007 / \mathrm{s} 00269-008-0261-3$. 


\title{
Thermal Diffusivity of Natural and Synthetic Garnet Solid Solution Series
}

\author{
Hauke Marquardt ${ }^{1}$, Steffen Ganschow ${ }^{2}$, Frank R. Schilling ${ }^{1}$ \\ ${ }^{1}$ GeoForschungsZentrum Potsdam, Telegrafenberg, 14473 Potsdam, Germany \\ ${ }^{2}$ Institute for Crystal Growth, Max Born-Str. 2, 12489 Berlin, Germany
}

hama@gfz-potsdam.de, +49 3312881894

\begin{abstract}
Knowledge of heat transport properties as a function of mineral- and rock-composition and temperature is of major relevance to understand and model heat transfer in the Earth's interior. A systematic study on 13 natural and 4 synthetic garnets was carried out in an attempt to obtain a better systematic understanding of the processes that affect the heat transport in minerals, especially the effect of chemical substitution in solid solution series. It is found that substitution significantly lowers the thermal diffusivity from end-member values for both synthetic and natural garnets with a minimum of thermal diffusivity at an intermediate composition. The thermal diffusivity as a function of the degree of substitution can be described by the approach of Padture and Klemens (1997). With increasing temperature the thermal diffusivity decreases due to phononphonon-scattering effects. A quantitative analysis of the high-temperature behaviour was carried out by using the model of Roufosse and Klemens (1974), which takes a lower limit of thermal diffusivity at elevated temperatures into account. The model allows for an extrapolation of the deduced room temperature thermal diffusivities to higher temperatures. Furthermore, the model was modified to determine the high temperature limit of the thermal diffusivity for all investigated natural garnets $D_{\min }$ to be $0.64 \pm 0.03 \mathrm{~mm}^{2} / \mathrm{s}$.
\end{abstract}

\section{Introduction}

Temperature gradients within the Earth are the driving force for many dynamic processes on various scales. To understand and model the evolvement of geological scenarios, for instance mantle convection (Yanagawa et al., 2005), knowledge of heat transport properties of the Earth's constituent phases is needed (e.g. O. L. Anderson, 1999; Hofmeister, 1999). As minerals exist with varying chemical composition, it is important to understand the effect of chemical variations on the thermal transport properties. It has been shown for a variety of solid solution series that a minimum in thermal transport properties occurs for an intermediate composition (e.g. Horai \& Simmons, 1969; Padture \& Klemens, 1997; Patel et al., 2001; Giesting \& Hofmeister, 2002; Giesting et al., 2004). Garnets are the ideal candidates for studying substitution-effects on thermal transport properties as they form a variety of solid solution series. Furthermore, minerals of the garnet group exist in a wide temperature and pressure range, what makes them one of the most abundant phases in the Earth's lower crust and mantle, especially in the transition zone (e.g. D. L. Anderson, 1989). Beside its relevance in geosciences, an improved understanding of heat transport properties in insulators is important for issues in material sciences, such as solid state laser design (Krupke et al., 1986), thermal barrier coatings (Padture \& Klemens, 1997), or electronic packaging (Weidenfeller et al., 2004). Most natural silicate garnets can be assigned to the ternary solid solution series pyralspite (pyrope-almandinespessartine) and ugrandite (uvarovite-grossular-andradite). Because natural garnets can neither be found as pure end-members in nature, nor be synthesized as single crystals in a sufficient size, we first investigated synthetic aluminium garnets in order to develop a basic understanding of the substitution-effect in the 
more easy-to-handle binary chemical system $\mathrm{Y}_{3} \mathrm{Al}_{5} \mathrm{O}_{12}(\mathrm{YAG})-\mathrm{Yb}_{3} \mathrm{Al}_{5} \mathrm{O}_{12}(\mathrm{YbAG})$ and subsequently applied the results to natural garnets.

$\mathrm{Y}_{\mathrm{x}} \mathrm{Yb}_{3-\mathrm{x}} \mathrm{Al}_{5} \mathrm{O}_{12}$ appeared almost perfectly suited for the current study because it was expected that crystals of arbitrary composition can be grown from the melt. This expectation was based on the similarity in thermophysical properties, i.e. melting temperature and enthalpy, of both end-members $\mathrm{Y}_{3} \mathrm{Al}_{5} \mathrm{O}_{12}$ and $\mathrm{Yb}_{3} \mathrm{Al}_{5} \mathrm{O}_{12}$ (Wu \& Pelton, 1992; Klimm et al., 2007). The YAG-YbAG system is of major interest for material sciences, as these crystals are widely-used for solid state lasers (e.g. Patel et al., 2001; Gaumé et al., 2003), where the thermal conductivity is a key parameter.

In addition to the composition dependence, thermal transport properties strongly change with temperature. The temperature effect on the heat transport depends on the heat transport mechanism. In the examined temperature range, an increase in temperature will lead to a decrease in thermal diffusivity if a phonon process dominates the heat transport. The maximum temperatures reached experimentally in this study vary between $300^{\circ} \mathrm{C}$ and $1200^{\circ} \mathrm{C}$. Pressure will result in an increase of thermal transport properties, discussions of the pressure effect can be found in Osako et al. (2004) and Hofmeister (2007a).

Hofmeister (2006) reported the thermal diffusivity of different natural and synthetic garnets up to high temperatures using the laser-flash method. Beside this study, there are only very few, but inconsistent, measurements on the thermal transport properties of garnets (tab. 1). Obviously, there is a lack of comprehensive thermal diffusivity studies, particularly with regard to compositional effects. This work is an attempt to systematically describe the thermal diffusivity of garnets as a function of chemical composition and temperature.

\section{Theoretical background}

Heat transport properties are described by thermal conductivity $\lambda$ and thermal diffusivity $D$, both are linked in a homogeneous body via volumetric heat capacity $c$ (e.g. Grigull \& Sandner, 1979):

$$
\lambda=D \cdot c \cdot \rho
$$

The thermal diffusivity $D$ describes the thermal equilibration process of a body in the presence of a temperature gradient and is given by (one dimensional)

$$
\frac{\partial T}{\partial t}=D \cdot\left(\frac{\partial^{2} T}{\partial x^{2}}\right)
$$

where $T$ is temperature, $t$ is time and $x$ is distance. The thermal diffusivity $D$ is represented by a symmetric second rank tensor. Therefore, cubic garnets behave isotropically with respect to thermal transport properties (e.g. Nye, 1985).

Thermal conductivity and thermal diffusivity in insulators are mainly the sum of radiative diffusive heat transfer and heat transport via lattice vibrations (phonons). The way to get a handle on the radiative component of heat transport in minerals is still under discussion (e.g. Shankland \& Nitsan, 1979; Hofmeister, 1999; Gibert et al., 2005; Hofmeister, 2005; Pertermann \& Hofmeister, 2006; Hofmeister, 2007b). This study focusses on the heat transport by phonons. By considering that a solid body behaves like a gas of phonons (Debye, 1914), one can describe the thermal diffusivity of phonons, according to the kinetic gas 
theory, as a diffusion of particles (phonons) through the body; the diffusion coefficient is given by the mean phonon velocity $v$ and the mean free path length of phonons $l$ :

$$
D=\frac{1}{3} \cdot v \cdot l
$$

The mean free path length $l$ describes the mean distance a phonon can travel without being scattered. Local density variations, such as atoms of different masses, act as one of the most efficient scattering mechanisms at ambient conditions. The solid solution series YAG-YbAG is perfectly suited for studying this effect due to the pronounced atomic mass difference between yttrium (88.91 $\mathrm{g} / \mathrm{mol})$ and ytterbium $(173.04 \mathrm{~g} / \mathrm{mol})$. The mean velocity of phonons $v$ can be approximated as the quadratic mean from the longitudinal and the transverse sound wave velocities $v_{p}, v_{s 1,2}$ :

$$
v=\sqrt{\frac{v_{p}^{2}+v_{s 1}^{2}+v_{s 2}^{2}}{3}}
$$

Padture and Klemens (1997) describe an approach to quantify the effect of substitution on the thermal conductivity in solid solution series, $k(X, T)$ can be written as follows:

$$
k(X, T)=k_{i} \sqrt{\frac{\chi \cdot T}{X(1-X)}} \tan ^{-1} \sqrt{\frac{X(1-X)}{\chi \cdot T}}
$$

where $k_{i}$ is the mechanical mixture of the endmember values, $X$ is the concentration of the substituting atom and $\chi$ is a constant. As the relation between thermal conductivity and thermal diffusivity is given by eq. 1 , this approach is also valid for $D(X, T)$.

Different models were used in previous studies to describe the thermal transport by phonons as a function of temperature (e.g. Zoth \& Haenel, 1988; Seipold, 1998; Höfer \& Schilling, 2002; Gibert et al., 2003; Gibert et al., 2005; Bruls et al., 2005; Ray et al., 2006). To the best of our knowledge, all are based on the empirical observation by Eucken (1911), which was later theoretically founded by Peierls (1929), that the thermal conductivity is linearly related to the inverse temperature. Hofmeister (2006) found that these models are not sufficient to describe the temperature dependent thermal diffusivity over the entire temperature range; instead, she used different polynomials to describe her data. In the present study, the model from Roufosse and Klemens (1973) and Roufosse and Klemens (1974) is used. This model extends the considerations of Peierls (1929) by taking a lower limit of the mean free path of phonons into account, and considering the spectral distribution of phonon frequencies as a function of temperature. According to these authors the thermal conductivity as a function of temperature at high temperatures is given by

$$
\lambda(T)=\frac{B}{T}\left[\frac{2}{3}\left(\frac{T_{1}}{T}\right)^{\frac{1}{2}}+\frac{1}{3}\left(\frac{T}{T_{1}}\right)\right](6),
$$

where $B$ and $T_{1}$ are material-specific constants that depend on physical properties, namely atomic mass, sound wave velocity, cell volume, and Grüneisen parameter 
(Roufosse \& Klemens, 1974). For the temperature-dependent thermal diffusivity, one derives as a first order approximation:

$$
D(T)=\frac{B^{\prime}}{T}\left[\frac{2}{3}\left(\frac{T_{1}}{T}\right)^{\frac{1}{2}}+\frac{1}{3}\left(\frac{T}{T_{1}}\right)\right] \text { (7) }
$$

Note that the conversion from equation 6 to equation 7 neglects the temperature dependence of both heat capacity and density.

\section{Samples}

The thermal diffusivities of 4 synthetic and 13 natural single crystals with garnet structure (tab. 2) were measured. All of the synthetic and most of the natural samples are cm-sized, gem-quality single crystals. The major selection criterions for the natural garnets were size and quality. Nevertheless, some fractured garnets were also used to enhance the compositional range of natural garnets.

Crystals with various compositions in the $\mathrm{Y}_{\mathrm{x}} \mathrm{Yb}_{3-\mathrm{x}} \mathrm{Al}_{5} \mathrm{O}_{12}$ system were grown using a conventional Czochralski technique with rf induction heating. The high purity $(5 \mathrm{~N})$ starting materials $\mathrm{Yb}_{2} \mathrm{O}_{3}, \mathrm{Y}_{2} \mathrm{O}_{3}$, and $\mathrm{Al}_{2} \mathrm{O}_{3}$ were mixed in a proper ratio and melted into a $40 \mathrm{ml}(38 \mathrm{~mm}$ diameter, $40 \mathrm{~mm}$ height $)$ iridium crucible surrounded by alumina and zirconia ceramic insulation. Crystals with 18 $\mathrm{mm}$ diameter were pulled on YbAG seeds oriented along [100] with a rate of $1-2$ $\mathrm{mm} / \mathrm{h}$. To prevent oxidation of the iridium crucible, all growth processes were carried out in protective $\left(\mathrm{N}_{2}\right)$ atmosphere. The as-grown crystals were of turquoise-blue (high $\mathrm{Yb}$ amount) or grass-green (low $\mathrm{Yb}$ amount) color that is believed to be caused mainly by occurrence of $\mathrm{Yb}^{2+}$ ions in the crystals due to low oxygen partial pressure during growth (Yang et al., 2002).

All samples were characterized by electron microprobe analysis (Cameca SX-50 with silicates and phosphates as standards) for chemical composition (tab. 3) and X-ray-diffraction (STOE Stadi P), in combination with Rietveldrefinement, for cell parameters and density (tab. 4). The mean phonon velocity (eq. 4) was determined by measuring the sound wave velocities of the synthetic crystals with an ultrasonic technique at 2 and $4 \mathrm{Mhz}$ natural frequencies, and by a linear extrapolation of literature data for the natural garnets (tab. 4). Two coplanar faces were cut and polished for the determination of thermal diffusivity and ultrasonic sound velocity. The upper surface was coated with silver to suppress radiative heat transport in thermal diffusivity experiments. The deviation from parallelism of the two faces is less than $0.5^{\circ}$. For the laser-flash experiments, the samples were coated with gold and graphite. The diameter of both samples was 12 $\mathrm{mm}$ and the thicknesses were $4.24 \mathrm{~mm}$ (YAG) and $2.25 \mathrm{~mm}$ (YbYAG-1).

\section{Experimental setup}

A transient method, which is closely related to flash methods described by Parker et al. (1961), is used to determine the thermal diffusivity as a function of temperature. The sample is placed in a furnace (fig. 1a), where a filament above the sample produces a short heat pulse. The resulting heat transfer to the sample is observed as a temperature change that is recorded between the filament and the 
sample. The temperature equilibration process is measured by a fast thermocouple underneath the sample as a function of time (fig. 1b). A fictive temperature-timecurve, one would expect at thermocouple 2 for a given thermal diffusivity, is calculated from the temperature-time-curve recorded above the sample (thermocouple 1) by using a finite-difference-algorithm (Schilling, 1999). The thermal diffusivity is systematically varied until the best agreement between calculated and measured temperature-time-curve at thermocouple 2 is achieved. Direct heat transfer and heat losses from the surfaces are taken into account (Schilling, 1999; Höfer \& Schilling, 2002). For this study, the evaluation procedure was modified to correct for absorption in the sample using the BeerLambert law. Experimental errors due to contact losses (Lee and Hasselmann, 1985) can be neglected in this method, when sample sizes are chosen accordingly. The internal precision of this method is better than $3 \%$ for sufficient sample sizes (Schilling, 1999; Höfer \& Schilling, 2002), the external uncertainty is smaller than $5 \%$. A more detailed description of the transient method and error analysis is given in Schilling (1999) and Höfer and Schilling (2002).

The stated accuracy of the transient method is verified in this study by comparing the results to measurements that were performed on the same samples using the laser-flash method (Netzsch LFA 427). The LFA measurements were carried out in argon atmosphere and the data were analysed with the built-in Netzsch software by using both the pulse correction and the radiation model. Details about this method are given in Bräuer et al. (1992) and Blumm and Lemarchand (2002).

\section{Results}

Thermal diffusivities of the studied natural garnets are between $1.21 \mathrm{~mm}^{2} / \mathrm{s}$ and $2.74 \mathrm{~mm}^{2} / \mathrm{s}$, whereas thermal diffusivities for the investigated synthetic garnets are between $2.01 \mathrm{~mm}^{2} / \mathrm{s}$ and $4.25 \mathrm{~mm}^{2} / \mathrm{s}$ (tab. 4). All measured crystals show a decrease in thermal diffusivity with increasing temperature (fig. 2, 3). The largest decrease in thermal diffusivity can be observed for the samples with the highest thermal diffusivites at room temperature. At elevated temperatures, thermal diffusivities of both synthetic and natural garnets seem to approach a constant value (fig. 3, 4). All shown data points are average values of at least four measurements at each temperature step. The scatter of the individual points is smaller than the stated uncertainty. The data obtained from the laser-flash method (Netzsch LFA 427) on two of our samples (fig. 3) and the results from the transient method coincide within the experimental uncertainties of the methods. The laser-flash derived YAG-data from Hofmeister (2006) are also shown for comparison.

\section{Discussion}

\section{Room-temperature behaviour}

It can be seen from the investigated YAG-YbAG solid solution series (fig. 4a) that the variation of thermal diffusivity with progressive substitution of yttrium by ytterbium is not represented by a simple arithmetic mean of the end-members's 
thermal diffusivities (mechanical mixture). A minimum is found for an intermediate composition due to increased phonon scattering at local mass differences. The approach of Padture and Klemens (1997) is used (eq. 5) to describe the thermal diffusivity as a function of the degree of substitution. Fig. 4 shows that their model represents our results within the experimental uncertainties. We determined a value of $2.58 \cdot 10^{-4} \mathrm{~K}^{-1}$ for the fitting parameter $\chi$. For comparison, the data points from Patel et al. (2001), which were measured at $19^{\circ} \mathrm{C}$, are also shown in fig. $4 \mathrm{a}$. The majority of the data points coincide with our measurements, however, two points are significantly lower than the model curve. Patel et al. (2001) do not give information on the method used or the uncertainty of their results. Consequently, it cannot be judged if the divergency is due to the quality of the data of Patel et al. (2001) or the model of Padture and Klemens (1997).

Natural garnets can be divided into two ternary solid solution series, pyralspite (pyrope $\left(\mathrm{Mg}_{3} \mathrm{Al}_{2} \mathrm{Si}_{3} \mathrm{O}_{12}\right)$ - almandine $\left(\mathrm{Fe}_{3} \mathrm{Al}_{2} \mathrm{Si}_{3} \mathrm{O}_{12}\right)$ - spessartine $\left(\mathrm{Mn}_{3} \mathrm{Al}_{2} \mathrm{Si}_{3} \mathrm{O}_{12}\right)$ ) and ugrandite (uvarovite $\left(\mathrm{Ca}_{3} \mathrm{Cr}_{2} \mathrm{Si}_{3} \mathrm{O}_{12}\right)$ - grossular $\left(\mathrm{Ca}_{3} \mathrm{Al}_{2} \mathrm{Si}_{3} \mathrm{O}_{12}\right)$ - andradite $\left.\left(\mathrm{Ca}_{3} \mathrm{Fe}_{2} \mathrm{Si}_{3} \mathrm{O}_{12}\right)\right)$. The pyralspite system is the focus of this discussion, because most of the investigated natural garnets belong to this series (tab. 3). In order to simplify this natural system and make it comparable to the binary solid solution series of the synthetic garnets, two simplifications are used. First, a fictive solid solution series between pyrope and almandine + spessartine is introduced. This is a feasible assumption, because, according to Hofmeister (2006), the heat transport properties of almandine $\left(\mathrm{Fe}_{3} \mathrm{Al}_{2} \mathrm{Si}_{3} \mathrm{O}_{12}\right)$ and spessartine $\left(\mathrm{Mn}_{3} \mathrm{Al}_{2} \mathrm{Si}_{3} \mathrm{O}_{12}\right)$ are comparable due to the similar infrared-spectra of almandine and spessartine (Hofmeister \& Chopelas, 1991) and the similar atomic masses of Mn and Fe. Similar thermal transport properties of Fe- and Mn-bearing minerals are also observed for olivines (Sowe \& Schilling, 2004). Secondly, the content of grossular, andradite, and uvarovite is neglected, and the chemical composition is recalculated to

$$
\frac{X_{\text {pyrope,recalculated }}+X_{\text {almandine, recalculated }}+X_{\text {spessartine,recalculated }}}{X_{\text {pyrope }}+X_{\text {almandine }}+X_{\text {spessartine }}+X_{\text {grossular }}+X_{\text {andradite }}+X_{\text {uvarovite }}}=1 \text { (8). }
$$

The thermal diffusivity is plotted versus the recalculated pyrope content (fig. 4b). Except for the pyrope-end-member, fig. $4 \mathrm{~b}$ only contains gem-quality crystals. The data points at $X_{\text {pyrope }}=0.35$ and $X_{\text {pyrope }}=0.69$ represent an average value of two samples with very similar composition (see tab. 3). Again, the approach of Padture and Klemens (1997) is well suited to describe our data $\left(\chi=12 \cdot 10^{-4} \mathrm{~K}^{-1}\right)$. Fig. $4 \mathrm{~b}$ also contains previously published data of Giesting and Hofmeister (2002) and Hofmeister (2006). The thermal diffusivity data from Giesting and Hofmeister (2002) are calculated from infrared spectra and it can be seen in fig. $4 \mathrm{~b}$ that their data also suggest a minimum, but the absolute values do not agree with the data of this study and the results from Hofmeister (2006). The experimental data measured with different techniques (laser-flash, transient method) agree within their uncertainties.

The observed data-scattering, especially of sample GrAlmPyr2, might be due to one or more of the following effects:

1. The grossular content of the samples varies between 1 and $16 \mathrm{wt} . \%$.

2. Incorporated $\mathrm{OH}$ and trace elements might influence the thermal diffusivity (Hofmeister et al., 2006; Branlund \& Hofmeister, 2007). 
3. Fe-and Mn-garnets are not equivalent with respect to thermal diffusivity.

According to the kinetic gas theory, thermal diffusivity is determined by the mean free path of phonons and the mean velocity of phonons (eq. 3). The difference in the mean velocity of phonons between the different samples is small compared to the difference in the mean free path (fig. 5). It is concluded that the characteristic behaviour of $D(X)$ in fig. 4 is mainly governed by the mean free path of phonons, whereas the mean phonon velocity is a second order effect and only gives a weighting to one of the end-members. It follows that the variation of thermal diffusivity of the investigated natural garnets is dominated by the mean free path (fig. 6).

\section{High-temperature behaviour}

All measured samples show a decrease of thermal diffusivity with increasing temperature; this is in agreement with the theory of phonon-phonon-interactions (Umklapp-Processes) (Peierls, 1929). The decrease is mainly due to a decrease of the mean free path length of phonons. The reduction of the mean free path of phonons is limited to a value determined by the interatomic distances, which are around $0.28 \mathrm{~nm}$ (oxygen-oxygen-distance) for garnets (e.g. Geiger \& Armbruster, 1997). As the variation of mean phonon velocity with temperature can be neglected, the thermal diffusivity approaches a constant value at high temperatures. From fig. 6 it can be roughly estimated that this value is in the order of $0.6 \mathrm{~mm}^{2} / \mathrm{s}$ for natural garnets.

The dominant scattering process changes with increasing temperature. At ambient conditions the differences in thermal diffusivities can be related to the different atomic masses and the resulting scattering of phonons. With increasing temperature, phonon-phonon-interactions (three phonon processes) become more efficient. This results in a decrease of the deviation from a mechanical mixture of the end-members's thermal diffusivities within the solid solution series of natural and synthetic garnets (fig. 4). At high temperatures the thermal diffusivity becomes nearly independent of the chemical composition.

The model of Roufosse and Klemens (1974) was applied to describe the high-temperature behaviour. The model describes our data very good, despite the facts that it was developed for very high temperatures and that the conversion from eq. 6 to eq. 7 is not strictly correct. We did not use polynomials as proposed by Hofmeister (2006) and Hofmeister (2007b), mainly because of two reasons. First, they do not allow for an extrapolation of our measured data to higher temperatures as shown in fig. 3. Secondly, the proposed polynomials need at least three constants to describe the experimental data. The model of Roufosse and Klemens (1974) contains only two fitting parameters and it is shown in fig. 3 that an extrapolation of our data with this model to higher temperatures is in good agreement with the LFA high temperature results.

The relation between the two regression constants $B^{\prime}, T_{1}$ and the thermal diffusivity at room temperature $D_{R T}$ is shown in fig. 7; an increase of both $B$ ' and $T_{l}$ with increasing $D_{R T}$ is observed. By assuming linear relations, one obtains the following equations:

$$
\begin{gathered}
B^{\prime}{ }_{n a t}=308.4 \mathrm{~K} \cdot D_{R T}-36.5 \mathrm{~mm}^{2} \mathrm{~K} / \mathrm{s}, T_{1, \text { nat }}=139 \mathrm{sK} / \mathrm{mm}^{2} \cdot D_{R T}+9.1 \mathrm{~K}(9) \\
B_{s y n}^{\prime}=140.3 \mathrm{~K} \cdot D_{R T}-306.1 \mathrm{~mm}^{2} \mathrm{~K} / \mathrm{s}, T_{1, s y n}=284.8 \mathrm{sK} / \mathrm{mm}^{2} \cdot D_{R T}-191.5 \mathrm{~K} \text { (10). }
\end{gathered}
$$


$B^{\prime}$ and $T_{1}$ in equation 7 can be substituted with the above relations to approximately calculate $D(T)$ for garnets in the pyralspite system and the YAGYbAG system from the room temperature thermal diffusivities.

\section{High temperature limit}

A lower limit of the thermal diffusivity is reached at high temperatures due to the lower limit of the mean free path of phonons. This limit is expected to be in the range of $0.6 \mathrm{~mm}^{2} / \mathrm{s}$ for the natural garnets as derived from fig. 6 . A more precise deduction of the high temperature limit is possible by modifying eq. 7 for infinite high temperatures; one derives

$$
D_{\min }(T \rightarrow \infty)=\frac{1}{3} \frac{B^{\prime}}{T_{1}}(11) .
$$

By assuming a constant high temperature limit, one expects a linear relation between $B$ ' and $T_{1}$, with a slope of $3 D_{\min }$ as illustrated in fig. 8 . This results in a minimum thermal diffusivity of $0.64 \pm 0.03 \mathrm{~mm}^{2} / \mathrm{s}$ for the natural garnets, which is in agreement with our rough estimation from fig. 6 and the values determined by Hofmeister (2006) at high temperatures.

\section{Conclusion:}

Solid solution series of both synthetic aluminium and natural silicate garnets show a minimum in thermal diffusivity at an intermediate composition due to the largest amount of phonon-scattering. The thermal diffusivity as a function of substitution $D(X, T)$ can be described by the approach of Padture and Klemens (1997). The constant that is needed in this model to describe the $D(X, T)$ behaviour was determined to be $2.58 \cdot 10^{-4} \mathrm{~K}^{-1}$ for the system $(\mathrm{Y}, \mathrm{Yb})_{3} \mathrm{Al}_{5} \mathrm{O}_{12}$ and $12 \cdot 10^{-4} \mathrm{~K}^{-1}$ for the pyralspite system.

At high temperatures, the thermal diffusivity becomes almost independent of the chemical composition. The model of Roufosse and Klemens (1974) describes $D(T)$ of the examined garnets very well and allows for an extrapolation of room temperature data to higher temperatures. Furthermore, the model was modified to determine the high-temperature-limit of the thermal diffusivity for the investigated natural garnets $D_{\min }$ to be $0.64 \pm 0.03 \mathrm{~mm}^{2} / \mathrm{s}$.

Acknowledgement: Many thanks to the institute for crystal growth in Berlin (IKZ) for producing and providing the synthetic garnets. We would also like to thank Netzsch GmbH for test measurements with the LFA 427. We would like to thank A. M. Hofmeister and two anonymous reviewers for their critical comments and helpful suggestions that helped to improve this manuscript. Many thanks to the entire section 4.1 at the GeoForschungsZentrum Potsdam for support, especially Kristin Gratz for discussions and technical assistance, Andreas Ebert for continuous support, Matthias Gottschalk for stimulating discussions, Gerhard Berger for microprobe sample preparation, Dieter Rhede for microprobe analysis and Andreas Hahn for Xray diffraction measurements. 

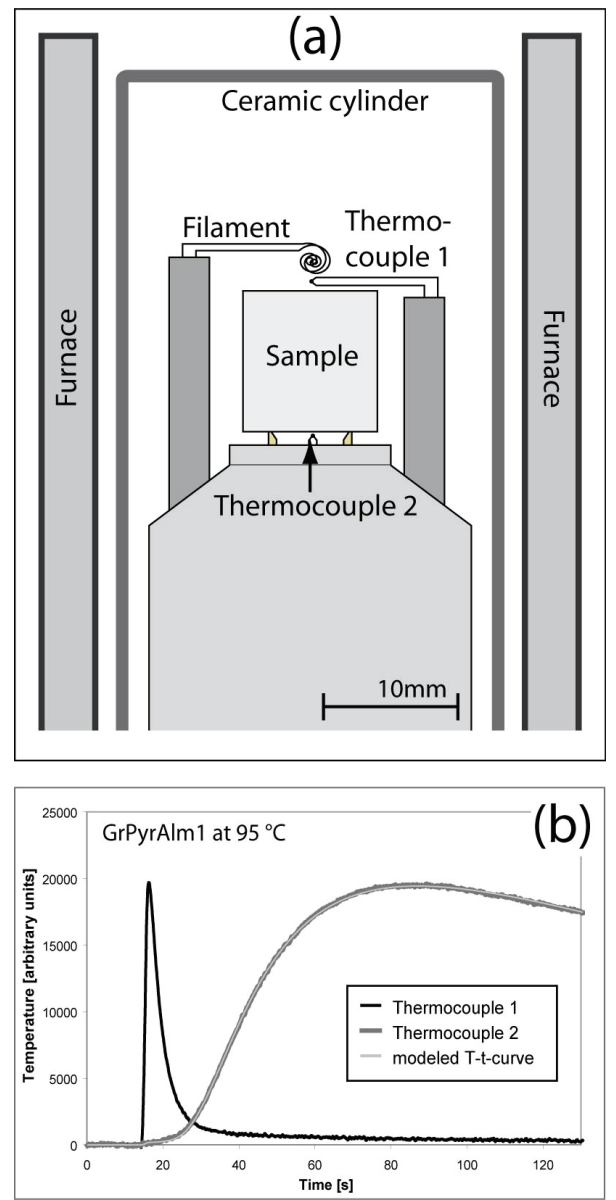

Figure 1: (a) Transient method to determine the thermal diffusivity as a function of temperature. (b) recorded temperature-time-curve at thermocouple 1 and 2. The modeled curve that is calculated from the finite-difference algorithm is also shown (see text for details).
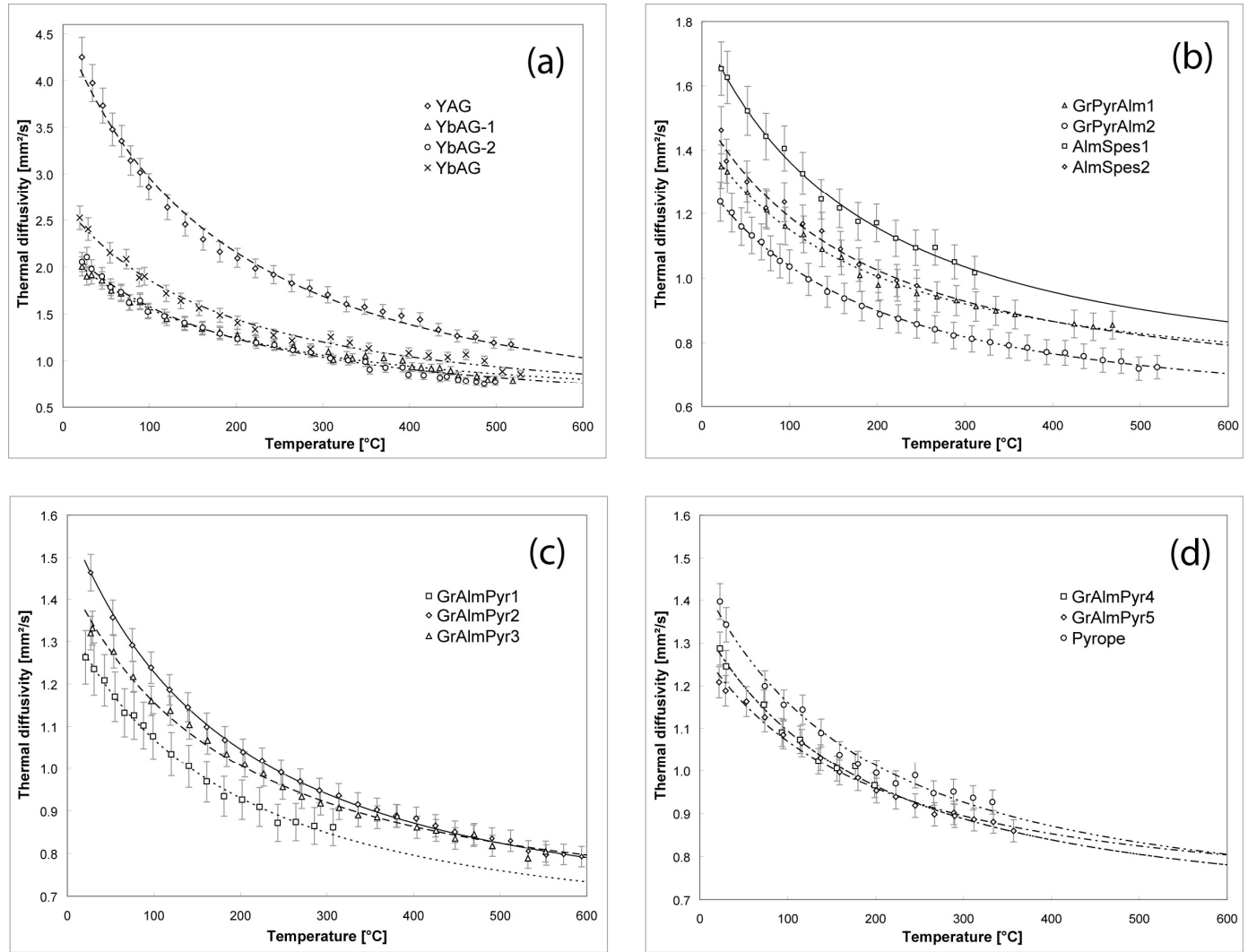
Figure 2: The thermal diffusivity as a function of temperature. (a) aluminium-garnets, (b) almandines and (c), (d) pyropes.

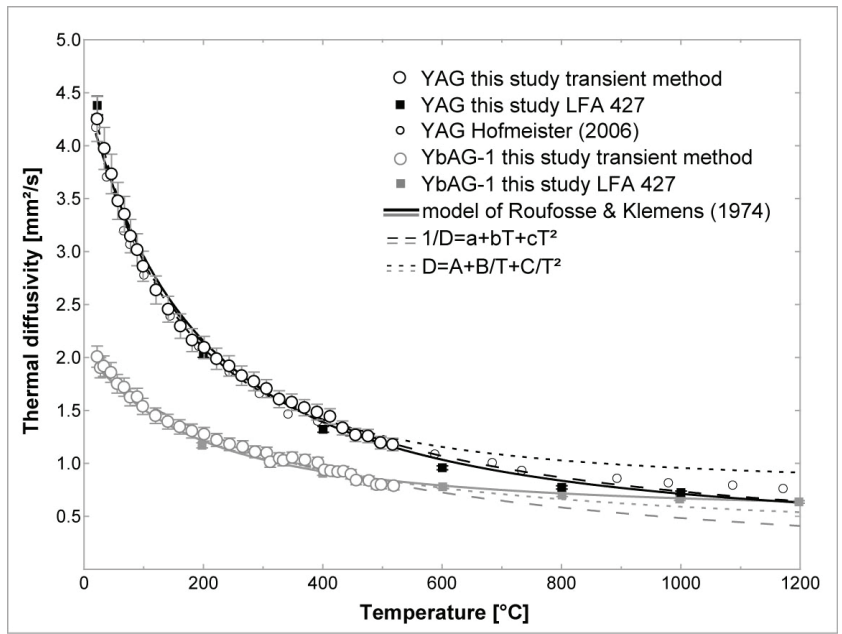

Figure 3: Comparison of thermal diffusivity data obtained with the transient method in this study with data obtained by laser-flash method in this study and by Hofmeister (2006). The data points corresponding to the transient method represent the average of at least four thermal diffusivity measurements at each temperature. The lines are regression curves to the data of the transient method that are calculated by using the model of Roufosse and Klemens (1974) and two different polynomials.
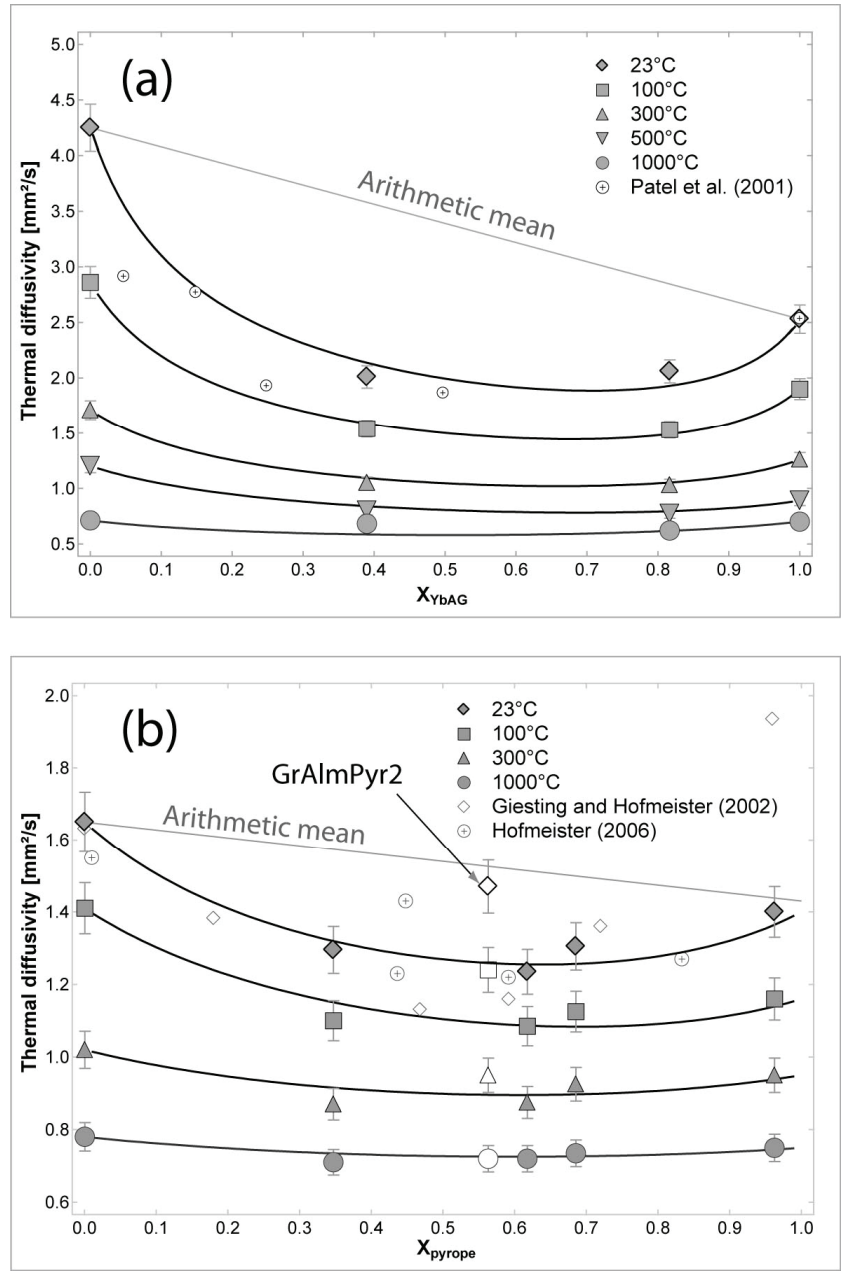

Figure 4: Thermal diffusivity as a function of (a) ytterbium-content in the system $\mathrm{Y}_{3} \mathrm{Al}_{5} \mathrm{O}_{12}$ $\mathrm{Yb}_{3} \mathrm{Al}_{5} \mathrm{O}_{12}$ and (b) pyrope-content in the pyralspite system at different temperatures. $D(X, T)$ can be described by the model of Padture and Klemens (1997). (a) contains also the data from Patel et al. 
(2001). (b) only contains the results of the gem-quality crystals, except for the pyrope endmember. The data points in (b) at $X_{\text {pyrope }}=0.35$ and $X_{\text {pyrope }}=0.69$ represent an average value of two samples. For comparison, (b) also contains data points from Giesting and Hofmeister (2002) and Hofmeister (2006). The thermal diffusivity at $1000{ }^{\circ} \mathrm{C}$ in (a) and (b) is extrapolated from our data by using the model of Roufosse and Klemens (1974).

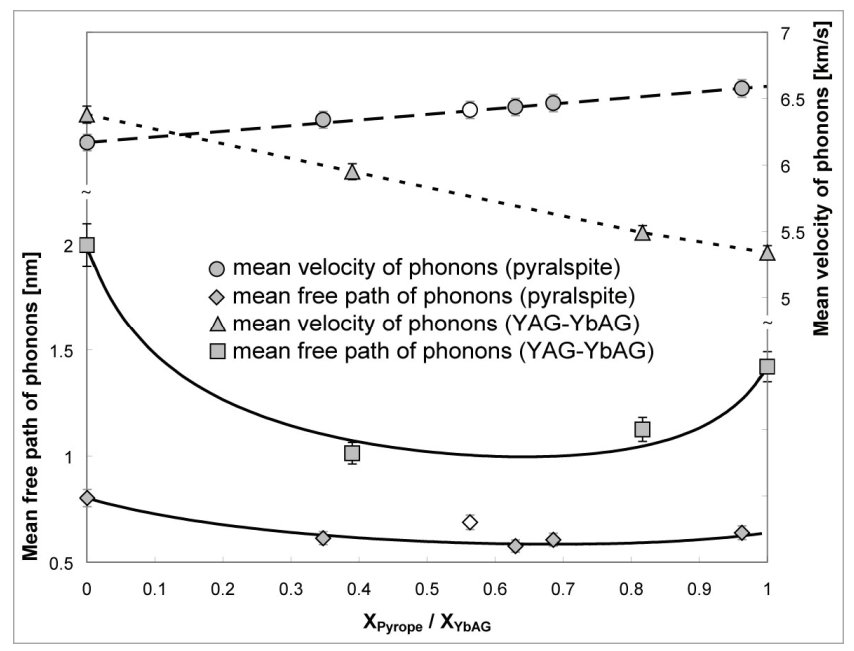

Figure 5: Mean velocity of phonons and mean free path of phonons as a function of ytterbiumcontent and pyrope-content. The mean free path length is calculated with eq. 3 . The velocity of phonons can be described by an arithmetic mean of the end-member values. The $l(X)$-curves are calculated with the approach of Padture and Klemens (1997).

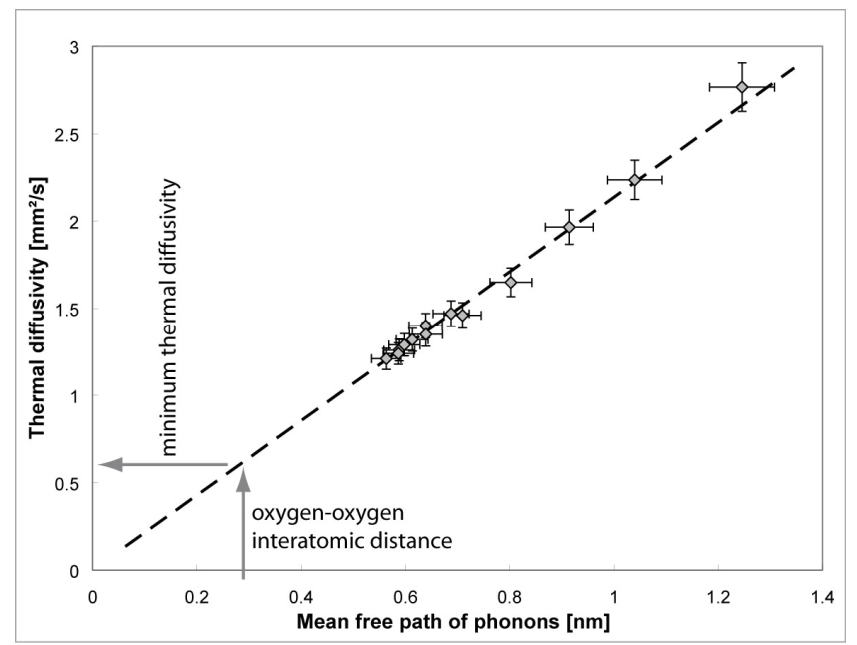

Figure 6: Thermal diffusivity of the natural garnets as a function of mean free path of phonons. The dashed line represents a linear dependency, which implies a constant mean phonon velocity. 


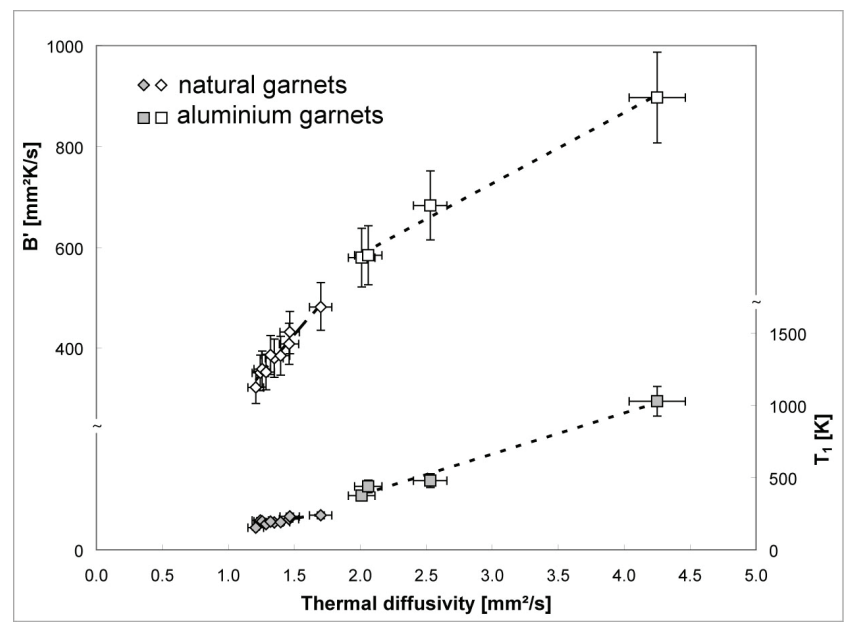

Figure 7: The constants $B^{\prime}$ and $T_{I}$ as a function of the room temperature thermal diffusivity $D_{R T}$.

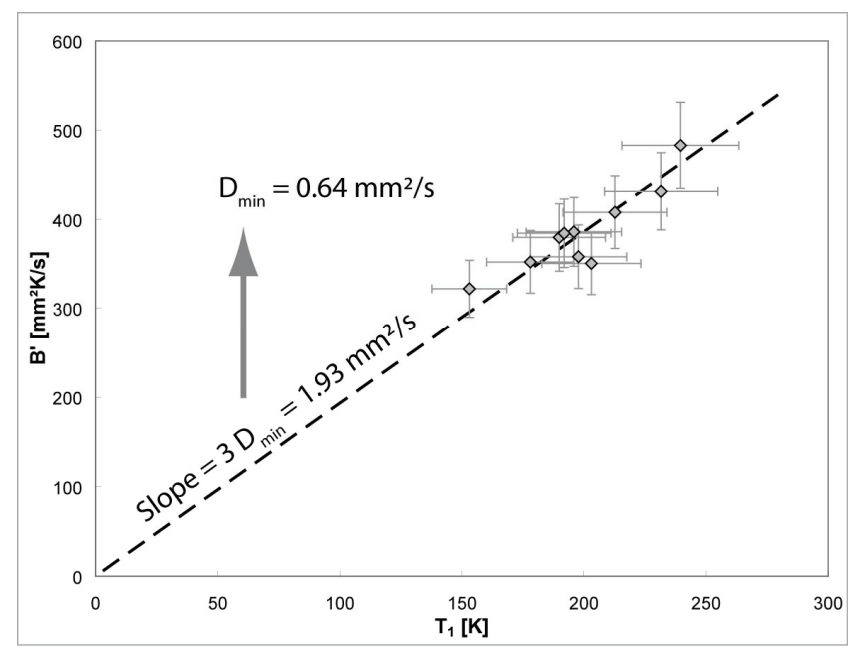

Figure 8: The relation between the constants $B^{\prime}$ and $T_{l}$ of natural garnets with the assumption of a constant lower limit of the thermal diffusivity $D_{\min }$. The slope equals $3 D_{\text {min }}$. 
Table 1: Thermal transport properties of garnets. Kan68: Kanamori et al. (1968), Hor69: Horai and Simmons (1969), Sla71: Slack and Oliver (1971), Zha84: Zharikov et al. (1984), Kru86: Krupke et al. (1986), Cha96: Chai et al. (1996), Pad97: Padture and Klemens (1997), Osa97, Osa04: Osako and Eiji (1997); Osako et al. (2004), Pat01: Patel et al. (2001), Kuw04: Kuwano et al. (2004), Mar05: Marquardt et al. (2005), Hof06: Hofmeister (2006), Sat06: Sato and Taira (2006). $\mathrm{a}, \mathrm{b}, \mathrm{c}, \mathrm{d}$ values are reported in terms of thermal conductivity and were converted to thermal diffusivity using eq. 1 . The reported thermal conductivity in $\mathrm{Wm}^{-1} \mathrm{~K}^{-1}$ is also given in brackets. The densities are a given, ${ }^{b, e}$ calculated from end-member densities, and ${ }^{\mathrm{c}, \mathrm{d}}$ measured in this study. The heat capacities are taken from: ${ }^{\mathrm{a}, \mathrm{b}}$ calculated from Robie et al. (1979); Bohlen et al. (1986); Robie et al. (1987) and Geiger and Armbruster (1997), "Sato and Taira (2006), ${ }^{\mathrm{d}, \mathrm{e}}$ calculated from oxide heat capacities. Ptgs $=$ picosecond transient grating spectroscopy. *Horai and Simmons (1969) measured natural samples and do not report exact compositions.

\begin{tabular}{|c|c|c|c|c|c|c|c|c|c|}
\hline \multicolumn{6}{|c|}{ Chemical composition [mol.\%] } & Quality & $\mathrm{D}\left[\mathrm{mm}^{2} / \mathrm{s}\right]$ & Author & Method \\
\hline \multicolumn{10}{|c|}{ Natural garnets } \\
\hline Py & $\mathrm{Al}$ & $\mathrm{Sp}$ & Uv & $\mathrm{Gr}$ & An & & & & \\
\hline 100.0 & 0.0 & 0.0 & 0.0 & 0.0 & 0.0 & dissolved & $0.97^{\mathrm{a}}(3.18)$ & Hor69* & needle probe \\
\hline 75.0 & 15.0 & 0.0 & 2.0 & 12.0 & 0.0 & gem & 1.27 & Hof06 & laser-flash \\
\hline 60.0 & 40.0 & 0.0 & 0.0 & 0.0 & 0.0 & unknown & 1.11 & Kan68 & angstrom \\
\hline 56.0 & 37.9 & 0.8 & 0.0 & 5.3 & 0.0 & gem & 1.22 & Hof06 & laser-flash \\
\hline 51.0 & 32.0 & 1.0 & 0.0 & 16.0 & 0.0 & unknown & 1.06 & Cha96 & ptgs \\
\hline 50.0 & 50.0 & 0.0 & 0.0 & 0.0 & 0.0 & unknown & 1.09 & Kan68 & angstrom \\
\hline 49.0 & 49.0 & 2.0 & 0.0 & 0.0 & 0.0 & gem & $1.37^{\mathrm{b}}(4.3)$ & Sla71 & unknown \\
\hline 44.0 & 56.0 & 0.0 & 0.0 & 0.0 & 0.0 & gem & $1.44^{\mathrm{b}}(4.5)$ & Sla71 & unknown \\
\hline 43.0 & 52.0 & 1.0 & 0.0 & 4.0 & 0.0 & gem & 1.43 & Hof06 & laser-flash \\
\hline 39.4 & 48.8 & 1.3 & 0.0 & 10.6 & 0.0 & fractured & 1.23 & Hof06 & laser-flash \\
\hline 35.0 & 43.5 & 1.7 & 0.0 & 19.8 & 0.0 & gem & 1.23 & Hof06 & laser-flash \\
\hline 25.0 & 73.0 & 1.0 & 0.0 & 1.0 & 0.0 & unknown & 1.19 & Osa04 & pulse heating \\
\hline 21.1 & 72.2 & 1.6 & 0.0 & 4.6 & 0.0 & fractured & 1.25 & Hof06 & laser-flash \\
\hline 17.0 & 76.0 & 7.0 & 0.0 & 0.0 & 0.0 & unknown & 1.18 & Osa97 & pulse heating \\
\hline 11.5 & 64.8 & 1.2 & 0.0 & 20.4 & 2.0 & fractured & 1.28 & Mar05 & transient \\
\hline 5.1 & 15.7 & 60.9 & 0.0 & 18.3 & 0.0 & fractured & 1.18 & Hof06 & laser-flash \\
\hline 5.0 & 72.0 & 3.0 & 3.0 & 17.0 & 0.0 & fractured & 1.04 & Hof06 & laser-flash \\
\hline 3.0 & 42.1 & 53.3 & 0.0 & 0.0 & 1.6 & fractured & 1.47 & Mar05 & transient \\
\hline 3.0 & 0.0 & 0.3 & 0.0 & 73.1 & 23.6 & fractured & 2.01 & Mar05 & transient \\
\hline 3.0 & 0.0 & 0.0 & 0.1 & 85.6 & 11.0 & gem+frac & 2.83 & Hof06 & laser-flash \\
\hline 3.0 & 0.0 & 0.0 & 5.3 & 89.3 & 2.4 & gem & 2.86 & Hof06 & laser-flash \\
\hline 1.0 & 61.0 & 37.0 & 0.0 & 1.0 & 0.0 & gem & 1.55 & Hof06 & laser-flash \\
\hline 0.6 & 1.6 & 0.4 & 0.0 & 79.3 & 18.1 & fractured & 2.77 & Hof06 & laser-flash \\
\hline 0.1 & 0.0 & 0.3 & 0.1 & 1.0 & 98.4 & rim frac. & 2.88 & Hof06 & laser-flash \\
\hline 0.0 & 100.0 & 0.0 & 0.0 & 0.0 & 0.0 & dissolved & $1.19^{\mathrm{a}}(3.31)$ & Hor69* & needle probe \\
\hline 0.0 & 0.0 & 100.0 & 0.0 & 0.0 & 0.0 & dissolved & $1.18^{\mathrm{a}}(3.4)$ & Hor69* & needle probe \\
\hline 0.0 & 0.0 & 0.0 & 0.0 & 0.0 & 100.0 & dissolved & $1.17^{\mathrm{a}}(3.09)$ & Hor69* & needle probe \\
\hline 0.0 & 3.0 & 5.0 & 0.0 & 15.0 & 77.0 & fractured & 2.02 & Hof06 & laser-flash \\
\hline 0.0 & 1.3 & 0.1 & 0.0 & 95.6 & 3.0 & gem & 2.79 & Hof06 & laser-flash \\
\hline 0.0 & 3.0 & 1.0 & 0.0 & 96.0 & 0.0 & gem & $2.54^{b}(7.2)$ & Sla71 & unknown \\
\hline 0.0 & 0.0 & 0.0 & 0.0 & 100.0 & 0.0 & dissolved & $1.98^{\mathrm{a}}(5.46)$ & Hor69* & needle probe \\
\hline \multicolumn{10}{|c|}{ Synthetic garnets } \\
\hline \multicolumn{6}{|c|}{ YAG } & polycrystal & $3.25^{\mathrm{c}}(8.8)$ & Pad97 & laser-flash \\
\hline \multicolumn{6}{|c|}{ YAG } & unknown & 3.66 & Kru86 & laser-flash \\
\hline \multicolumn{6}{|c|}{ YAG } & gem & $3.73^{\mathrm{c}}(10.1)$ & Sat06 & laser-flash \\
\hline \multicolumn{6}{|c|}{ YAG } & gem & $3.80^{\mathrm{c}}(10.3)$ & Sla71 & unknown \\
\hline \multicolumn{6}{|c|}{ YAG } & gem & 4.13 & Hof06 & laser-flash \\
\hline \multicolumn{6}{|c|}{ YAG } & unknown & 4.50 & Zha84 & unknown \\
\hline \multicolumn{6}{|c|}{ YAG } & gem & 4.73 & Kuw04 & laser-flash \\
\hline \multicolumn{6}{|c|}{$\left(\mathrm{Y}_{2.85} \mathrm{Yb}_{0.15}\right) \mathrm{AG}$} & gem & $2.92^{\mathrm{e}}(8.03)$ & Pat01 & unknown \\
\hline \multicolumn{6}{|c|}{$\left(\mathrm{Y}_{2.55} \mathrm{Yb}_{0.45}\right) \mathrm{AG}$} & gem & $2.77^{\mathrm{e}}(7.76)$ & Pat01 & unknown \\
\hline \multicolumn{6}{|c|}{$\left(\mathrm{Y}_{2.25} \mathrm{Yb}_{0.75}\right) \mathrm{AG}$} & gem & $1.93^{\mathrm{e}}(5.48)$ & Pat01 & unknown \\
\hline \multicolumn{6}{|c|}{$\left(\mathrm{Y}_{1.50} \mathrm{Yb}_{1.50}\right) \mathrm{AG}$} & gem & $1.87^{\mathrm{e}}(5.42)$ & Pat01 & unknown \\
\hline \multicolumn{6}{|c|}{$\mathrm{YbAG}$} & gem & $2.37^{\mathrm{d}}(6.9)$ & Sla71 & unknown \\
\hline
\end{tabular}


Table 2: Investigated natural and synthetic garnets. Length is the distance parallel to the direction of measurement. Surface gives the area perpendicular to the direction of measurement.

\begin{tabular}{|l|c|c|c|c|}
\hline Sample & Origin & Quality & $\begin{array}{c}\text { Length } \\
{[\mathrm{mm}]}\end{array}$ & $\begin{array}{c}\text { Surface } \\
{\left[\mathrm{mm}^{2}\right]}\end{array}$ \\
\hline \multicolumn{4}{|c|}{ Synthetic samples } \\
\hline $\mathrm{Y}_{3} \mathrm{Al}_{5} \mathrm{O}_{12}(\mathrm{YAG})$ & IKZ Berlin & gem & 14.9 & 113 \\
\hline $\mathrm{Y}_{1.83} \mathrm{Yb}_{1.17} \mathrm{Al}_{5} \mathrm{O}_{12}(\mathrm{YbYAG}-1)$ & IKZ Berlin & gem & 14.6 & 127 \\
\hline $\mathrm{Y}_{0.55} \mathrm{Yb}_{2.45} \mathrm{Al}_{5} \mathrm{O}_{12}(\mathrm{YbYAG}-2)$ & IKZ Berlin & gem & 13.9 & 126 \\
\hline $\mathrm{Yb}_{3} \mathrm{Al}_{5} \mathrm{O}_{12}(\mathrm{YbAG})$ & IKZ Berlin & gem & 14.8 & 116 \\
\hline \multicolumn{5}{|c|}{ Natural samples } \\
\hline AlmSpes1 & Brasil & gem & 11.6 & 222 \\
\hline GrAnd+Ti1 & Mali & inclusions & 11.7 & 231 \\
\hline GrAlmPyr1 & unknown & gem & 10.8 & 68 \\
\hline GrAlmPyr2 & East Africa & gem & 8.5 & 103 \\
\hline GrAlmPyr3 & unknown & gem & 9.6 & 199 \\
\hline GrAlmPyr4 & unknown & gem & 11.3 & 131 \\
\hline GrPyrAlm1 & unknown & gem & 14.7 & 88 \\
\hline GrPyrAlm2 & unknown & gem & 11.0 & 116 \\
\hline GrAlmPyr5 & Mongolia & fractured & 9.8 & 39 \\
\hline AndGr & Sibiria & alterated & 11.4 & 180 \\
\hline AlmSpes2 & Brazil & fractured & 11.1 & 151 \\
\hline GrAnd+Ti2 & Italy & fractured & 9.9 & 150 \\
\hline Pyrope & Italy & fractured & 10.6 & 115 \\
\hline
\end{tabular}

Table 3: Electron microprobe analysis of the studied natural samples reported in terms of garnet end-members (mol.\%). The tagged $(*)$ samples contain about 2 wt. $\% \mathrm{TiO}_{2}$.

\begin{tabular}{|l|c|c|c|c|c|c|}
\hline Sample & $\begin{array}{c}\text { Pyrope } \\
\mathrm{Mg}_{3} \mathrm{Al}_{2} \mathrm{Si}_{3} \mathrm{O}_{12}\end{array}$ & $\begin{array}{c}\text { Almandine } \\
\mathrm{Fe}_{3} \mathrm{Al}_{2} \mathrm{Si}_{3} \mathrm{O}_{12}\end{array}$ & $\begin{array}{c}\text { Spessartine } \\
\mathrm{Mn}_{3} \mathrm{Al}_{2} \mathrm{Si}_{3} \mathrm{O}_{12}\end{array}$ & $\begin{array}{c}\text { Uvarovite } \\
\mathrm{Ca}_{3} \mathrm{Cr}_{2} \mathrm{~S}_{3} \mathrm{O}_{12}\end{array}$ & $\begin{array}{c}\text { Grossular } \\
\mathrm{Ca}_{3} \mathrm{Al}_{2} \mathrm{~S}_{3} \mathrm{O}_{12}\end{array}$ & $\begin{array}{c}\text { Andradite } \\
\mathrm{Ca}_{3} \mathrm{e}_{2} \mathrm{Si}_{3} \mathrm{O}_{12}\end{array}$ \\
\hline AlmSpes1 & 0.05 & 45.67 & 53.42 & 0.03 & 0.83 & 0.00 \\
\hline AlmSpes2 & 0.02 & 41.18 & 57.91 & 0.02 & 0.87 & 0.00 \\
\hline GrAnd+Ti1* & 1.75 & 0.04 & 0.23 & 0.07 & 37.34 & 60.58 \\
\hline AndGr & 2.77 & 0.00 & 0.27 & 0.05 & 77.32 & 19.60 \\
\hline GrPyrAlm2 & 24.73 & 54.67 & 3.37 & 0.03 & 15.89 & 1.31 \\
\hline GrPyrAlm1 & 25.66 & 55.99 & 2.91 & 0.04 & 14.18 & 1.23 \\
\hline GrAlmPyr2 & 44.54 & 41.30 & 1.34 & 0.03 & 12.79 & 0.00 \\
\hline GrAlmPyr1 & 50.73 & 37.18 & 1.54 & 0.07 & 10.34 & 0.13 \\
\hline GrAlmPyr5 & 50.33 & 33.74 & 0.95 & 0.02 & 13.14 & 1.81 \\
\hline GrAlmPyr4 & 54.11 & 28.95 & 0.91 & 0.02 & 14.53 & 1.46 \\
\hline Pyrop & 53.76 & 30.43 & 0.79 & 0.18 & 12.71 & 2.13 \\
\hline
\end{tabular}


Table 4: Lattice constant $a_{0}$ and x-ray density $\rho_{\text {xray }}$ were deduced by x-ray powder diffraction and Rietveld-refinement in combination with electron microprobe analysis. Sound wave velocities $v_{\mathrm{s}}$ and $v_{\mathrm{p}}$ were measured with piezoelectric transducers and excitation frequencies of 2 and $4 \mathrm{Mhz}$ (arithmetic mean, $<1 \%$ uncertainty) for the synthetic garnets and are calculated as arithmetic mean from the end-member values taken from Sumino and Anderson (1982) and Wang and Ji (2001) for the natural garnets. The mean velocity of phonons $v_{\text {phonon }}$ is calculated from eq. 4 . The thermal diffusivity is measured at around $23{ }^{\circ} \mathrm{C}$.

\begin{tabular}{|l|c|c|c|c|c|c|}
\hline Sample & $\begin{array}{c}\rho_{\text {xray }} \\
{\left[\mathrm{g} / \mathrm{cm}^{3}\right]}\end{array}$ & $\begin{array}{c}a_{0} \\
{[\AA]}\end{array}$ & $\begin{array}{c}v_{p[100]} \\
{[\mathrm{km} / \mathrm{s}]}\end{array}$ & $\begin{array}{c}v_{s[100]} \\
{[\mathrm{km} / \mathrm{s}]}\end{array}$ & $\begin{array}{c}v_{\text {phonon }} \\
{[\mathrm{km} / \mathrm{s}]}\end{array}$ & $\begin{array}{c}D \\
{\left[\mathrm{~mm}^{2} / \mathrm{s}\right]}\end{array}$ \\
\hline Yynthetic samples \\
\hline YbYAG-1 & 4.55 & $12.0072(5)$ & 8.41 & 5.06 & 6.38 & 4.25 \\
\hline YbYAG-2 & 6.23 & $11.9795(5)$ & 7.87 & 4.70 & 5.95 & 2.01 \\
\hline YbAG & 6.61 & $11.9514(5)$ & 7.25 & 4.34 & 5.49 & 2.06 \\
\hline \multicolumn{7}{|c|}{ Natural samples } \\
\hline AlmSpes1 & 4.27 & $11.5735(5)$ & 8.38 & 4.69 & 6.17 & 1.65 \\
\hline GrAnd +Ti1 & 3.74 & $11.9942(5)$ & 8.73 & 4.92 & 6.45 & 1.97 \\
\hline GrAlmPyr1 & 3.84 & $11.5307(5)$ & 8.72 & 4.89 & 6.43 & 1.26 \\
\hline GrAlmPyr2 & 3.87 & $11.5372(5)$ & 8.70 & 4.89 & 6.41 & 1.47 \\
\hline GrAlmPyr3 & 3.80 & $11.5417(5)$ & 8.76 & 4.92 & 6.46 & 1.32 \\
\hline GrAlmPyr4 & 3.78 & $11.5503(5)$ & 8.78 & 4.93 & 6.47 & 1.29 \\
\hline GrPyrAlm1 & 4.00 & $11.5598(5)$ & 8.60 & 4.82 & 6.34 & 1.35 \\
\hline GrPyrAlm2 & 4.00 & $11.5677(5)$ & 8.61 & 4.83 & 6.34 & 1.24 \\
\hline GrAlmPyr5 & 3.82 & $11.5488(5)$ & 8.74 & 4.91 & 6.45 & 1.21 \\
\hline AndGr & 3.69 & $11.8755(5)$ & 8.98 & 5.13 & 6.66 & 2.74 \\
\hline AlmSpes2 & 4.25 & $11.5844(5)$ & 8.38 & 4.69 & 6.17 & 1.46 \\
\hline GrAnd +Ti2 & 3.76 & $11.9647(5)$ & 8.74 & 4.93 & 6.45 & 2.24 \\
\hline Pyrop & 3.60 & $11.4554(5)$ & 8.92 & 5.01 & 6.58 & 1.40 \\
\hline
\end{tabular}


Anderson, D. L. (1989). Theory of the Earth. Blackwell Scientific Publications

Anderson, O. L. (1999). Mantle convection: A thermal balancing act. Science, 283 (5408):1652-1653.

Blumm, J., Lemarchand, S. (2002). Influence of test conditions on the accuracy of laser flash measurements. High Temp-High Press 34:523-528.

Bohlen, S. R., Dollase, W. A., Wall, V. J. (1986). Calibration and applications of spinel equilibria in the system FeO-Al2O3-SiO 2 (thermobarometer). J Petrol, 27 (5):1143-1156.

Branlund, J. M., Hofmeister, A. M. (2007). Thermal diffusivity of quartz to $1,000^{\circ} \mathrm{C}$ : effects of impurities and the $\alpha-\beta$ phase transition. Phys Chem Miner 34:581-595, doi: 10.1007/s00269-007-0173-7

Bräuer, H., Dusza, L., Schulz, B. (1992). New laser flash equipment LFA 427. Interceram 41:489-492.

Bruls, R. J., Hintzen, H. T., Metselaar, R. (2005). A new estimation method for the intrinsic thermal conductivity of nonmetallic compounds: A case study for $\mathrm{MgSiN}_{2}, \mathrm{AlN}$ and b-Si $\mathrm{N}_{4}$ ceramics. J Eur Ceram Soc 25:767-779.

Chai, M., Brown, J. M., Slutsky, L. J. (1996). Thermal diffusivity of mantle minerals. Phys Chem Miner 23 (7):470-475.

Debye, P. (1914). Vorträge über die kinetische Theorie der Materie und der Elektrizität. B. G. Teubner, Berlin.

Eucken, A. (1911). Uber die Temperaturabhängigkeit der Wärmeleitfähigkeit fester Nichtmetalle. Ann Phys Leipzig, IV (34):185-221.

Gaumé, R., Viana, B., Vivien, D., Roger, J.-P., Fournier, D. (2003). A simple model for the prediction of thermal conductivity in pure and doped insulating crystals. Appl Phys Lett 83 (7): 1355-1357.

Geiger, C. A., Armbruster, T. (1997). $\mathrm{Mn}_{3} \mathrm{Al}_{2} \mathrm{Si}_{3} \mathrm{O}_{12}$ spessartine and $\mathrm{Ca}_{3} \mathrm{Al}_{2} \mathrm{Si}_{3} \mathrm{O}_{12}$ grossular garnet; structural dynamic and thermodynamic properties. Am Mineral 82 (7-8):740-747.

Gibert, B., Schilling, F. R., Gratz, K., Tommasi, A. (2005). Thermal diffusivity of olivine single crystals and a dunite at high temperature: Evidence for heat transfer by radiation in the upper mantle. Phys Earth Planet Inter 151 (1-2):129-141.

Gibert, B., Seipold, U., Tommasi, A., Mainprice, D. (2003). Thermal diffusivity of upper mantle rocks: Influence of temperature, pressure, and the deformation fabric. J Geophys Res 108(B8), 2359, doi:10.1029/2002JB002108

Giesting, P. A., Hofmeister, A. M. (2002). Thermal conductivity of disordered garnets from infrared spectroscopy. Phys Rev B 65: 144305.

Giesting, P. A., Hofmeister, A. M., Wopenka, B., Gwanmesia, G. D., Jolliff, B. L. (2004). Thermal conductivity and thermodynamics of majoritic garnets; implications for the transition zone. Earth Planet Sci Lett 218 (1-2): 45-56.

Grigull, U., Sandner, H. (1979). Wärmeleitung. Springer, Berlin.

Höfer, M., Schilling, F. R. (2002). Heat transfer in quartz, orthoclase, and sanidine at elevated temperatures. Phys Chem Miner 29:571-584.

Hofmeister, A. M. (1999). Mantle values of thermal conductivity and the geotherm from phonon lifetimes. Science 283 (5408):1699-1706.

Hofmeister, A. M. (2005). Dependence of diffusive radiative transfer on grainsize, temperature, and fecontent: Implications for mantle processes. J Geodyn 40:51-72.

Hofmeister, A. M. (2006). Thermal diffusivity of garnets at high temperature. Phys Chem Miner 33 (1):4562.

Hofmeister, A. M. (2007a). Pressure dependence of thermal transport properties. Proc Natl Acad Sci 104(22): 9192-9197.

Hofmeister, A. M., Pertermann, M. and Branlund, J. M. (2007b). Thermal conductivity of the Earth. In G. Schubert (Ed. in Chief), Treatise in Geophysics, V. 2 Mineral Physics (G.D. Price, ed.) (pp. 543578). Elsevier, The Netherlands.

Hofmeister, A. M., Chopelas, A. (1991). Vibrational spectroscopy of end-member silicate garnets. Phys Chem Miner 17 (6):503-526.

Hofmeister, A. M., Pertermann, M., Branlund, J. M., Whittington, A. G. (2006). Geophysical implications of reduction in thermal conductivity due to hydration. Geophys Res Lett 33(11), L11310, doi:10.1029/2006GL026036.

Horai, K. i., Simmons, G. (1969). Thermal conductivity of rock-forming minerals. Earth Planet Sci Lett 6 (5):359-368.

Kanamori, H., Fujii, N., Mizutani, H. (1968). Thermal diffusivity measurement of rock-forming minerals from 300 to $1,100^{\circ} \mathrm{K}$. J Geoph Res 73 (2):595-605.

Klimm, D., Ganschow, S., Pajaczkowska, A., Lipinska, L. (2007). On the solubility of $\mathrm{Nd}^{3+}$ in $\mathrm{Y}_{3} \mathrm{Al}_{5} \mathrm{O}_{12} . \mathrm{J}$ Alloys Comp 436: 204-208.

Krupke, W., Shinn, M., Marion, J., Caird, J., Stokowski, S. (1986). Spectroscopic, optical, and thermomechanical properties of neodymiumand chromium-doped gadolinium scandium gallium garnet. J Opt Soc Am B 3 (1):102-114. 
Kuwano, Y., Suda, K., Ishizawa, N., Yamada, T. (2004). Crystal growth and properties of $(\mathrm{Lu}, \mathrm{Y})_{3} \mathrm{Al}_{5} \mathrm{O}_{12}$. J Cryst Growth 260 (1-2):159-165.

Lee, H. L., Hasselmann, D. P. H. (1985). Comparison of data for thermal diffusivity obtained by laser-flash method using thermocouple and photodetector. J Am Ceram Soc 68 (1): C12-C13.

Marquardt, H., Schilling, F. R., Gratz, K. (2005). Thermal diffusivity of garnets as a function of temperature. Ber Dtsch Mineral Ges, Beih Eur J Mineral 17 (1):87.

Nye, J. F. (1985). Physical properties of crystals. Clarendon Press, Oxford.

Osako, M., Eiji, I. (1997). Simultaneous thermal diffusivity and thermal conductivity measurements of mantle materials up to $10 \mathrm{GPa}$. Tech Rep ISEI A(67):1-6.

Osako, M., Ito, E., Yoneda, A. (2004). Simultaneous measurements of thermal conductivity and thermal diffusivity for garnet and olivine under high pressure. Phys Earth Planet Inter 143 (1-2): 311-320.

Padture, N. P., Klemens, P. G. (1997). Low thermal conductivity in garnets. J Am Ceram Soc 80 (4):10181020 .

Parker, W. J., Jenkins, R. J., Butler, C. P., Abbott, G. L. (1961). Flash method of determining thermal diffusivity, heat capacity, and thermal conductivity. J Appl Phys 32 (9):1679-1684.

Patel, F. D., Honea, E. C., Speth, J., Payne, S. A., Hutcheson, R., Equall, R. (2001). Laser demonstration of $\mathrm{Yb}_{3} \mathrm{Al}_{5} \mathrm{O}_{12}(\mathrm{YbAG})$ and materials properties of highly doped $\mathrm{Yb}$ : YAG. IEEE J Quantum Electronics 37 (1):135-144.

Peierls, R. (1929). Zur kinetischen Theorie der Wärmeleitung in Kristallen. Ann Phys, 395 (5(3)): 10551101.

Pertermann, M., Hofmeister, A. M. (2006). Thermal diffusivity of olivine group minerals at high temperatures. Am Miner, 91:1747-1760.

Ray, L., Förster, H.-J., Schilling, F. R., Förster, A. (2006). Thermal diffusivity of felsic to mafic granulites at elevated temperatures. Earth Planet Sci Lett, doi:10.1016/j.epsl.2006.09.010.

Robie, R. A., Bin, Z., Hemingway, B. S., Barton, M. D. (1987). Heat capacity and thermodynamic properties of andradite garnet, $\mathrm{Ca}_{2} \mathrm{Fe}_{3} \mathrm{Si}_{3} \mathrm{O}_{12}$ between 10 to $1000 \mathrm{~K}$ and revised values for $\Delta \mathrm{f} \mathrm{G}_{\mathrm{m}}$ (298.15 K) of hedenbergite and wollastonite. Geochim Cosmochim Acta 51: 2219-2224.

Robie, R. A., Hemingway, B. S., Fisher, J. R. (1979). Thermodynamic properties of minerals and related substances at $298.15 \mathrm{~K}$ and 1 bar $\left(10^{5}\right.$ pascals $)$ pressure and at higher temperatures. US Geol Surv Bull

Roufosse, M. C., Klemens, P. G. (1973). Thermal conductivity of complex dielectric crystals. Phys Rev B 7 (12):5379-5386.

Roufosse, M. C., Klemens, P. G. (1974). Lattice thermal conductivity of minerals at high temperatures. J Geophys Res 79 (5):703-705.

Sato, Y., Taira, T. (2006). The studies of thermal conductivity in $\mathrm{GdVO}_{4}, \mathrm{YVO}_{4}$ and $\mathrm{Y}_{3} \mathrm{Al}_{5} \mathrm{O}_{12}$ measured by quasi-one-dimensional flash method. Optics express 14 (22):10528-10536.

Schilling, F. R. (1999). A transient technique to measure thermal diffusivity at elevated temperatures. Eur J Miner $11(6): 11151124$.

Seipold, U. (1998). Temperature dependence of thermal transport properties of crystalline rocks; a general law. In Heat flow and the structure of the lithosphere; IV (Vol. 291; 1-4, p. 161-171). Amsterdam, Netherlands: Elsevier.

Shankland, T. J., Nitsan, U. (1979). Optical absorption and radiative heat transfer in olivine at high temperature. J Geophys Res 84 (B4):1603-1610.

Slack, G. A., Oliver, D. W. (1971). Thermal conductivity of garnets and phonon scattering by rare-earth ions. Phys Rev B 4 (2):592-609.

Sowe, M., Schilling, F. R. (2004). Diploma thesis.

Sumino, Y., Anderson, O. L. (1982). Elastic constants of minerals. In R. S. Carmichael (Ed.), Handbook of physical properties of rocks (Vol. 3, p. 39-138). CRC Press, Boca Raton, Florida.

Wang, Z., Ji, S. (2001). Elasticity of six polycrystalline silicate garnets at pressure up to $3.0 \mathrm{GPa}$. Am Miner 86 (10):1209-1218.

Weidenfeller, B., Höfer, M., Schilling, F. R. (2004). Thermal conductivity, thermal diffusivity, and specific heat capacity of particle filled polypropylene. Composites: Part A 35:423-429.

Wu, P., Pelton, A.D. (1992). Coupled thermodynamic-phase diagram assessment of the rare earth oxidealuminium oxide binary systems. J Alloys Comp 179: 259-287.

Yanagawa, T. K. B., Nakada, M., Yuen, D. A. (2005). Influence of lattice thermal conductivity on thermal convection with strongly temperature dependent viscosity. Earth, Planets and Space 57 (1): 15-28.

Yang, P., Deng, P., Yin, Z. (2002). Concentration quenching in Yb:YAG, J Luminescence 97: 51-54.

Zharikov, E. V., Kitaeva, V. F., Osiko, V. V., Rustamov, I. R., Sobolev, N. N. (1984). Elastic, photoelastic, and thermo-physical properties of gadolinium-scandium-gallium-garnet. Sov Phys Solid State 26: 922-923. 
Zoth, G., Haenel, R. (1988). Thermal conductivity. In R. Haenel, L. Rybach, \& L. Stegena (Eds.), Handbook of terrestrial heat-flow density determination (pp. 449-466). Kluwer Acadamic Publishers. 